\title{
Herpes simplex virus encephalitis
}

INSERM

\section{Source}

INSERM. (1999). Orphanet: an online rare disease and orphan drug data base. Herpes simplex virus encephalitis. ORPHA:1930

Herpes simplex virus encephalitis (HSVE) is caused by the infection of the central nervous system by Herpes simplex virus (HSV) that could have a devastating clinical course and a potentially fatal outcome particularly with delay or lack of treatment. HSVE often involves the frontal and temporal lobes, usually asymmetrically, resulting in personality changes, cognitive impairment, aphasia, seizures, and focal weakness. 